\title{
Smoke knows no boundaries: legal strategies for environmental tobacco smoke incursions into the home within multi-unit residential dwellings
}

\author{
Robert L Kline
}

\begin{abstract}
Objective-To describe legal theories that non-smoking residents of multiple occupancy buildings may employ when affected by environmental tobacco smoke (ETS) from neighbouring units.

Design-Legal research was conducted in several US states. Research was performed among statutes and regulations. State health regulations were examined as well as common law claims of nuisance, warranties of habitability, and the right of quiet enjoyment.

Results-Through the use of state regulations, such as a sanitary code, several states provide general language for protecting the health of residents in multi-unit buildings. State law also supports more traditional claims of nuisance, warranties of habitability, and the right of quiet enjoyment.

Conclusions-The use of state regulations has the potential to provide an effective, existing vehicle for resolution of ETS incursion problems. The general health protection language of the regulations, in conjunction with the latest evidence of the harmful effects of ETS, gives state agencies authority to regulate environmental tobacco smoke incursions among apartments in multi-unit dwellings. Where state regulations are not available, other common law legal remedies may be available.

(Tobacco Control 2000;9:201-205)
\end{abstract}

Keywords: environmental tobacco smoke; legal strategies; multiple occupancy dwellings

This article examines regulatory and common law legal theories available to address the problem of environmental tobacco smoke (ETS) incursion into the homes of non-smoking residents of multi-unit dwellings. Non-smoking residents may use existing state regulations, such as sanitary codes, as a mechanism for legal action to prevent or limit incursion of ETS into non-smokers' apartments or condominiums in multiple occupancy residential buildings. The advantage of this strategy is that it employs an administrative system for correction of health violations that is already in place and accepted. No legislative action is necessary; no new legal theory need be created. It merely involves an application of existing law and scientific knowledge to specific facts by a Board of Health (the Board). Where the Board decision is appealed to a local court, the court may choose to defer to the administrative body's judgment in its area of expertise. Rather than a contentious issue of property rights where a jury must determine the appropriate interpretation of complex scientific evidence, the posture of the case will be an administrative law determination by a judge regarding the authority of the Board of Health. The burden of proof will be on the landlord to show that the Board acted arbitrarily and capriciously, not on an individual ETS victim to prove either the dangers of ETS or the sufficiency of exposure to implicate these dangers.

The advantage of maintaining the case in this posture is that the parties will not be neighbour v. neighbour but instead will be the landlord v. the Board. This eliminates the issue of the smoker's right to privacy in the home and focuses on the landlord providing the nonsmoking tenant with safe living conditions. The landlord, as owner and economically responsible party, is the best party to correct physical defects in the building that allow for ETS incursion. This approach is proactive and relies on scientific expertise of a government agency rather than a litigation model that relies on legal expertise and a confrontation between private parties.

\section{Health effects of ETS}

Numerous health agencies and scientific studies have determined that ETS imposes serious health risks on non-smokers. The Massachusetts Department of Public Health determined that ETS "can cause allergies, cancer, including lung cancer; and respiratory disease, especially in children whose parents smoke and in people who already have lung problems. It can aggravate heart disease and irritate the eyes, nose, throat and airways."

ETS causes the death of an estimated 3000 non-smokers per year from lung cancer. ETS also causes the death of approximately 50000 people per year due to ETS related heart disease. ${ }^{2}$ ETS has been identified as a possible causal factor in sudden infant death syndrome (SIDS), which is the leading cause of death in infants between 1 month and 1 year old. ${ }^{3}$

ETS also causes non-fatal but serious health risks to those exposed to it. ETS exposure may cause immediate health consequences including alterations in blood chemistry, effects on blood vessels and the heart muscle, and the ability of the heart to respond to the stress of reduced oxygen delivery. ${ }^{2}$ Short term exposure to ETS increases the carbon monoxide in the 
blood, reduces the ability of the heart muscle to convert oxygen into adenosine triphosphate (ATP), and increases the likelihood of the formation of blood clots. ${ }^{2}$

Although most studies focus on the effects of ETS on individuals who live with smokers, the qualitative nature of the studies are transferable to ETS incursion cases because the non-smoking tenant is still exposed to the toxic substances present in ETS. A lesser degree of exposure may exist but some fraction of the health effects and increase in risk still remains. ${ }^{5}$ Scientists have not determined any safe threshold level of ETS. Even very low concentrations of ETS will affect children under 2 years old and those with respiratory handicaps such as asthma. Courts have recognised that exposure to ETS is sufficiently harmful to give rise to a cause of action. ${ }^{6}{ }^{7}$

The scientific evidence gathering procedure can be relatively simple. The Board of Health inspector or an environmental health specialist would place an active monitor in the affected space to measure nicotine as a gas. Assuming that the tenant is a non-smoker, a positive reading for nicotine would provide good evidence to allow an inference that other gases and particulate matter of ETS exist as well.

ETS incursion as a violation of state health and safety codes

Each state in the USA has some regulatory mechanism to protect the health of its citizens living in multi-unit dwellings. The regulation may take the form of a sanitary code, a housing code, a landlord tenant regulation, or a municipal code. Each approach tends to set forth the standards by which some public health body may take action in the event of a violation, or grants rights to a resident whose health may be affected by his neighbours' actions.

These regulations usually list specific examples of code violations, although the presence of ETS as a violation is unlikely. An important tool for the success of this approach is the presence, at the end of this list, of a "catch-all" clause using broad language of "other violations" as determined by the regulatory agency. ${ }^{8}$ Regulation, case law or experience will determine the standard to be applied by a health inspector to such non-enumerated conditions (for example, the non-enumerated condition may have to "endanger health and safety/well being of an occupant" to be included as a health threat). ${ }^{8}$

The literature regarding ETS exposure must support the specific complaints by nonsmoking tenants in order to meet the standards necessary under the code. A Board determination that a particular health threat exists in a particular situation would merely be applying well-accepted scientific conclusions by widely acknowledged experts using the latest scientific findings. If a violation is found, the regulatory body's procedure or duty under these circumstances may include writing a fine, ordering repairs, or reporting the infraction to some other agency. Repairs might require caulking where ETS incursions occur, installing plastic smoke blockers behind electrical outlets, and correcting problems with the ventilation systems. The landlord may also enforce lease provisions against the smoker to prevent sanitary code violations. ${ }^{9}$

The rights of the landlord are often set out under the regulatory scheme. There are several issues a regulatory body may have to confront. How long does the landlord have to make repairs? Is there a penalty to the landlord for failure to repair? May the regulatory agency make a repair and charge the landlord for the cost? Some regulations use penalties as an economic incentive for the landlord (that is, each day the violation exists is considered a new violation).

Most administrative regulations will provide an appeals process for the landlord. ${ }^{10}$ The evidentiary standards and the legal standard of review applied during the appeal process will vary by state. The appellate body may also have a process for acceptance of general scientific data, such as ETS research. If the internal regulatory appeal process finds against the landlord, but the landlord still does not cooperate, the regulatory body may need to bring the landlord to court. The court will, in most cases, defer to the agency's expertise.

Specific states approach this problem in similar but distinct fashions. In Massachusetts the state sanitary code specifically sets forth that the Board inspectors are empowered to "determine if any ... other conditions, are conditions which may endanger or materially impair the health or safety, and well-being of an occupant or the public." "11 The drafters of the code anticipated that non-enumerated violations would exist and be subject to sanction. ${ }^{12}$ ETS is not specifically included, but the code states that the listed conditions "are specifically not intended as an exhaustive enumeration of such conditions." $\$ 11$

Connecticut's code regulating landlordtenant relations empowers the municipal department of health to determine whether ventilation or other sanitary conditions pose a threat to health, and if so to order the landlord to correct the unsanitary condition. ${ }^{13}$ In Delaware a landlord must maintain a rental unit in such condition so that it does not endanger the health, welfare or safety of the tenants. ${ }^{14}$ The statute permits local boards of health to determine whether a dwelling has become unfit as a living place and a cause of nuisance or sickness to the occupants. ${ }^{15}$ If so the local board of health may direct the owner to "cleanse" the premises. ${ }^{15}$ Colorado's Department of Public Health and Environment has been granted the power and the duty "to establish and enforce standards for exposure to environmental conditions, . . that may be necessary for the protection of public health. ${ }^{16}$ Furthermore, Colorado county and district health departments are given the power and duty to "make any necessary sanitary and health investigations and inspections . . . as to any matters affecting public health within the jurisdiction." ${ }^{17}$ States that do not contain such 
general provisions in the state statutes may leave sanitary code issues to municipal governments.

In summary, the state sanitary code approach offers several advantages. An existing body of law provides a framework for applying health science to a societal problem. An administrative body (either the local board of health or the state department of public health) will have determined the dangers of ETS making it less likely that a lengthy and costly court battle need be waged to "prove" well accepted science. The posture of the case will be a local health enforcement agency seeking to uphold the health and safety versus a landlord who, with some repairs, could resolve the problem. It thus removes the politically contentious issue of smokers' "rights" in their residences. Procedurally the burden will be on the landlord to show the Board acted unreasonably, and not on the Board to justify the exact details of ETS science. Finally, the landlord is the economically responsible party who is most able to act to correct the ETS incursion as opposed to a more transient smoking tenant.

\section{Other legal courses of action}

There are a variety of legal courses of action that tenants and owners of condominiums can use to try and stop a neighbour's drifting tobacco smoke from entering their home. These legal rights require that the adversely affected parties go to court to enforce their rights.

\section{NUISANCE}

A private nuisance is a non-trespassory invasion of another's interest in the private use and enjoyment of land. The invasion must be intentional and unreasonable, and must consist of an act or the failure to act under circumstances where there is a duty to take positive action to prevent or abate the interference. The invasion also must cause significant harm. ${ }^{18}$

To be intentional, an invasion must be carried out by an actor who purposefully causes the invasion, and knows, or should have known, that the invasion is resulting from the actor's conduct. ${ }^{19}$ It need not be ill inspired. Smoking a cigarette with knowledge that the smoke from the cigarette is substantially certain to drift into a neighbouring dwelling is, therefore, intentionally invading another's interest in land. An initial complaint to the smoking neighbour should be enough to put him on notice.

The issue then becomes whether the invasion is unreasonable. To be unreasonable, courts employ a balancing test to determine whether the seriousness of the harm outweighs the usefulness of the actor's conduct. Factors include: "(a) The extent of the harm involved; (b) the character of the harm involved; (c) the social value that the law attaches to the type of use or enjoyment invaded; (d) the suitability of the particular use or enjoyment invaded to the character of the locality; and (e) the burden on the person harmed of avoiding the harm." ${ }^{20}$
Cigarette smoke that drifts from one apartment to another and that causes non-smoking apartment residents serious discomfort and impairs their health may be an actionable nuisance. This is easy to understand if we apply the gravity of harm versus utility of conduct test to a typical ETS situation.

First, the harm caused by the tobacco smoke drifting from one apartment or condominium to another must be substantial and it must be significant enough to affect an ordinary person. Watery eyes by themselves probably will not make a case, nor will the drifting smoke from just a few cigarettes per day. But, if the non-smokers felt sick, or they were forced out of their home on occasion, and their house smelled, a court would be more likely to take action. It is important to remember, however, that exposure to ETS is dangerous to people's health, especially children's health. A court should take this fact into consideration given the appropriate documentation.

Second, the character of the harm involved is an important prong in determining the seriousness of drifting smoke relative to nuisance. Secondhand tobacco smoke is poisonous, irritating and, with prolonged exposure, can be deadly, particularly for young children or for those suffering from respiratory ailments. Smoke in apartment buildings travels through ventilation systems, through common areas, through windows and through walls. The burden on a tenant suffering from ETS to avoid drifting smoke is quite high.

The court must balance the gravity of the harm with the utility or usefulness of the conduct of the other person. ${ }^{21}$ The social value of the conduct, in this case smoking, is an important consideration in evaluating utility. It is difficult to assign any particular social value to smoking cigarettes, pipes, or cigars, aside from the simple right to use one's property as one wishes. Nor can smoking be said to be particularly suitable to its locality if it is interfering with the rights and health of others. A smoker can prevent or avoid an invasion of smoke. The smoker may merely stop or cut down on smoking, or smoke in an area where the smoke is confined or does not bother those affected. Since the act of smoking in one's own home possesses little social value, the argument that it is difficult to quit has little merit in the gravity of harm versus utility of conduct equation. ${ }^{22}$ Indeed, all the smoker needs to do is smoke outside or in a room from which air does not enter the non-smoker's apartment.

COVENANT OF QUIET ENJOYMENT

The right of quiet enjoyment addresses the tenant's right to freedom from serious intrusions with his tenancy "such as acts or omissions that impair the character and value of the leased premises". ${ }^{23}$ Landlords may be held responsible for the actions of third parties beyond their control. ${ }^{24}$

Clauses in the standard lease give the landlord the right to curb the smoking tenant's violations related to ETS incursions. The provisions relate to "Disturbance, Illegal Use" 25 and "Other Regulations". ${ }^{26}$ A landlord's failure 
to enforce the provisions gives the non-smoking tenant the right to sue the landlord for violation of the right to quiet enjoyment. ${ }^{27}$

The Massachusetts Housing Court recently found that ETS incursion from one rental unit to another constitutes a breach of the covenant of quiet enjoyment. ${ }^{28}$ Tenants rented a residential apartment above a restaurant and bar. The tenants made an uncontested assertion that levels of ETS incursion from the bar were significant. The tenants withheld rent for three months and the landlord began eviction proceedings. The tenants asserted as a defence that the landlord had violated their right of quiet enjoyment of the premises. The court held for the tenants that the landlord had breached the warranty of habitability, the statutory right of quiet enjoyment, and the consumer protection statute. The court awarded damages and ordered correction of the ETS incursion. ${ }^{29}$

WARRANTY OF HABITABILITY

All states have an implied warranty of habitability for rental. ${ }^{30}$ The warranty dictates that a landlord must provide residential rental premises fit for human occupation - that there are no latent or patent defects in the facilities - from the inception of the rental agreement through its entire term. ${ }^{31}$

The obligation of the landlord to abide by the warranty applies even when he or she is not at fault or has had no reasonable opportunity to make repairs. In essence, "the landlord's liability without fault is merely an economic burden; the tenant living in an uninhabitable building suffers a loss of shelter, a necessity." 32 In effect, the landlord may be held liable even as an innocent party; the warranty of habitability is not designed to penalise the landlord for misbehaviour, nor is it based on notions of moral sanction or deterrence. Likewise, when a problem exists, the landlord has an obligation to fix it immediately and completely, to bring it into compliance with the state sanitary code.

As discussed in the section regarding the state sanitary code, there is sufficient scientific evidence to justify holding that ETS endangers or materially impairs the health of the residents. Once a health inspector makes a determination that ETS incursion has occurred the non-smoking tenant would be able to use that as evidence of a material breach of the lease and of the warranty of habitability. The burden would be on the landlord to dispute the health inspector's findings.

Under a theory of warranty of habitability the court will determine whether a material breach of the lease has occurred by applying a set of factors to the circumstances of each case. ${ }^{33}$ The non-inclusive list of factors cited by the court include: "(a) the seriousness of the claimed defects and their effects on the dwelling's habitability; (b) the length of time the defects persist; (c) whether the landlord or his agent received written or oral notice of the defects; (d) the possibility that the residence could be made habitable within a reasonable time; and (e) whether the defects resulted from abnormal conduct or use by the tenant." 34

Applying these factors to the typical ETS incursion problem, the more serious the incursion the more likely the premises would not be habitable. The defect would probably continue to exist even after notice, the landlord should be put on notice early in the process, and repairs should be attempted. The tenant would be a non-smoker and therefore not likely to have contributed to the problem.

A report from a health inspector on the presence and dangers of ETS in the dwelling would help to show the landlord violated the habitability standards. The court, however, would perform its own factual review of the evidence and would determine "the seriousness" of the health threat. This might lead to a protracted evidentiary battle over ETS science. The merits and conclusions of the science favours the non-smoking tenant, but the lengthy process would be more likely to favour a landlord with deeper pockets.

\section{Conclusion}

There are several legal theories available for residents of multiple dwelling residential buildings who are affected by ETS incursion. Each is premised on the existence of a harm to the non-smoking resident. The health science literature is now available to demonstrate the harm and thus support the legal theories. The non-smoking resident must produce evidence of ETS incursion but in some instances need not show immediate negative health impacts. The scientific literature suggests that exposure to ETS is harmful over a long period. Courts are beginning to recognise that ETS exposure in some circumstances may be the basis of a cause of action. The non-smoking resident may pursue legal action in court or request the Board of Health use its powers to protect his or her health.

The author would like to express his gratitude to Professor Richard Daynard, Mark Gottlieb, Edward Sweda, Leslie Harroun, Liliana Mangiafico, and Lydia Berez for sharing research and providing feedback as this article evolved. The Massachusetts Tobacco Control Program provided funding for this research.

1 Massachusetts Department of Health, Public Health Fact Sheet, Second Hand Smoke, May 1988. The Department also lists areas where smoking in public areas is permitted and prohibited as of 1988 , but does not specifically address the issue of ETS incursion into private dwellings. 2 Glantz SA, Parmley WW. Passive smoking and heart disease. Circulation 1991;83:1-12.

3 California Environmental Protection Agency. Health effects of exposure to environmental tobacco smoke. Final Report. California: CEPA, 1997.

4 Stefanidis C, Vlachopoulos C, Tsiamis E, et al. Unfavorable effects of passive smoking on aortic function Ann Intern Med

5 Repace JL, Lowrey AH. An enforceable indoor air quality standard for environmental tobacco smoke in the workplace. Risk Analysis 1993;13:463-72.

6 Helling v. McKinney, 113 S.Ct. 2475 (1993). One court stated "the weight of scientific authority is such that there may be significant health consequences from involuntary exposure to tobacco smoke ... it is now generally accepted within the scientific community that the direct ingestion of tobacco smoke results in adverse health effects."

7 Avery v. Powell, 695 F. Supp. 632 (D.N.H. 1988) In the case of prisoners exposed to ETS in a residential type facility the Supreme Court denied the government's motion to dismiss the case and remanded the case to allow the prisdismiss the case and remanded the oner to present evidence of the degree of ETS exposure
and the level of harm caused. 105 CMR 410.750

9 See section of this paper regarding covenant of quiet enjoyment, supra.
men section of 
10105 CMR 410.850-853.

11 105 CMR 410.700. (emphasis added)

12 The Supreme Judicial Court of Massachusetts has stated that "[ $\mathrm{t}]$ here may be instances where conditions not covered by the Code regulations render the apartment uninhabitable." Boston Housing Authority v. Hemingway, 293 N.E.2d 831, 844 n.15 (Mass. 1973)

13 Conn.Gen. Stat. Section $47 a-52$.

14 Delaware Code Annotated Title 25, Section 5305 and Section 5303(a)(2).

15 Delaware Code Annotated Title 16, Section 305.

16 Colorado Revised Statutes, Section 25-1-107(t).

17 Colorado Revised Statutes, Section 25-1-506(1)(j).

18 Restatement (Second) of Torts.

19 Hall v. Phillips, 231 Neb. 269, 273, 436 N.W.2d 139, 143 (1989).

(Second) of Torts Section 827.

21 Courts will examine "(a) the social value that the law attaches to the primary purpose of the conduct; (b) the attaches to the primary purpose of the conduct; (b) the
suitability of the conduct to the character of the locality; and (c) the impracticability of preventing or avoiding the and (c) the

22 Moreover, smoking is no more of a fundamental right than shooting-up or snorting heroin or cocaine. Fagen v. Axelrod, 146 Misc.2d at 297, 550 N.Y.S.2d at 559. If people do have a general "right of privacy" to smoke the New York legislation merely requires them to exercise it where it does not harm others. "There is no differentiation between classes of citizens by this law. Those who smoke have never in law been recognized as a distinct class." Fagen v. Axelrod at 298, 559 .

23 Simon v. Solomon, 385 Mass. 91, 100, 431 N.E.2d 556, 564-565 (quoting Winchester v. O'Brien, 266 Mass. 33, 36, 164 N.E. 807 (1929). M.G.L. C 186 Sec. 14 (1992 ed.).

24 Simon v. Solomon, 385 Mass at 103, 431 N.E. $2 d$ at 565. The court found the landlord liable for breach of covenant of quiet enjoyment where the flooding of the tenant's apartment with water containing sewage was a result of other tenants using unauthorized washing machines or introducing objects into waste stacks, despite landlord's introducing objects into waste stacks, despite landlord's argument that it was unable to cont
action or the source of the flooding.

25 "Neither the Lessee nor his family, friends, relatives, invitees visitors agents or servants shall make or suffer any unlawful, noisy or otherwise offensive use of the leased premises, nor commit or permit any nuisance thereon ... nor create any substantial interference with the rights, comfort, safety or enjoyment of the Lessor or other occupants of the same or any other apartment." Paragraph 11, Standard Form Apartment Lease, Rental Housing Association of the Greater Boston Real Estate Board, 1996 ed. as reprinted in "Landlord's Rights and Duties in Massachusetts", Joseph P. DiBlasi, Sphinx Publishing, 1997.

26 "The Lessee agrees to conform to such lawful rules and regulations which are reasonably related to the purpose and provisions of this lease, as shall from time to time be established by the Lessor in the future for the safety, care, cleanliness, or orderly conduct of the leased premises and the building of which they are a part, and for the benefit, safety, comfort, and convenience of all the occupants of said building." Paragraph 18, Standard Form Apartment Lease, Rental Housing Association of the Greater Boston Real Estate Board, 1996 ed. as reprinted in "Landlord's Rights and Duties in Massachusetts", Joseph P. DiBlasi, Sphinx Publishing, 1997 .

27 Blackett v. Olanoff, 371 Mass. 714, 358 N.E. 2d 817 (1977).

Dworkin v. Paley, 638 N.E.2d 636 (Ohio Ct. App. 1994).

28 50-58 Gainsborough Street Realty Trust v. Haile, Housing Court, City of Boston, MA No. 98-/0/2/2/7/9/, June 8, 1998.

29 Id. at 33-35

0 "in the rental of any premises for dwelling purposes ...there is an implied warranty that the premises are fit for human occupation ..." Boston Housing Authority v. Hemingway, 293 N.E. 2 d 831, 843 (1973).

31 See Cruz Management Co., Inc. v. Thomas, 417 Mass. 782, 633 N.E.2d 390 (1994). (Management company was assessed damages for failing to remedy violations of heat, hot water, infestation, smoke detector, window and wiring, and fire escape State Sanitary Code violations); Hemingway, 293 N.E.2d 831 (1973) (Court found that under a way, $293 \mathrm{~N}$.. $.2 \mathrm{~d}$ 831 (1973) (Court found that under a written or oral lease there is animp Code and local heatwealth regulations that may not be waived by any provision of the lease or rental agreement, where breach of the warranty

32 Berman \& Sons, Inc. v. Jefferson, 379 Mass. 196, 200-201, 396 N.E.2d 981, 984-985 (1979). Simon v. Solomon, 385 Mass. 91, 96, 431 N.E.2d 556, 561 (1982)

33 Hemingway, 293 N.E.2d at 843 .

34 Id. at $843-44$. 